\title{
Design on Registration and Query System for Sports Test Scores of Students
}

\author{
Fengcheng Tang \\ College of Education and Sports, Bohai University, Jinzhou, 121013, China \\ 1106108759@qq.com
}

Keywords: registration inquiry; function module; sports test scores; IPO; detailed design

\begin{abstract}
With the extensive application of the network, the degree of access to information continues to strengthen, for students, fast query student scores is to represent the general trend. In order to improve the sports test scores query speed and accuracy, this paper designs student' sports test scores registered and query software. First, carry on the function module structure design, he software function is divided into students' basic information maintenance, scores management, scores registration, query, delete, modify, add, and other functions; Then, designs the logical structure of the database table; Finally, use IPO diagram gives the detailed design of software. The software implements registration and query for sports test scores, more convenient and rapid, has improved management efficiency and office productivity.
\end{abstract}

\section{Introduction}

Through sport test, it can for the teachers teaching achievements and students' physical quality to make accurate judgments. The test results are recorded in different ways, different results corresponding to different scores, which relates to a conversion process between them. For sports teachers, to all students in the sport test result are recorded and converted into the corresponding sports scores, which is a very large amount of work, if teachers rely on the traditional manual way, not only inefficiency, but also very likely to cause omissions and data loss [1]. Therefore, for the sports teachers of college, the need for a scientific, intelligent sports scores registered and query system, through the application of such a system, not only to help teachers quickly and accurately recorded on students' sports scores, classification and summary, reduce teacher workload, improve work efficiency, but also according to sports test data to determine the physical condition of the student, and to formulate the corresponding exercise plan according to the different physique, to physical condition of students carry on track evaluation, thus improving student for awareness of physical exercise to master their physical changes and improve the enthusiasm of physical exercise, ultimately help the school to achieve the improvement of students' comprehensive quality education and physical education.

\section{School Sports Work Standard}

The Ministry of education issued a "the basic standards of high school sports work" in 2014, hereinafter referred to as the "basic standard." It is the basic requirement for full-time colleges and universities sports work, is the important basis to measure the sports work of colleges and universities, not assessment and inspection for universities. "Standard" tightly to teaching, improve students' physical fitness level of education as a basic point of College Physical Education and foothold, the university sports development planning, teachers resources, resource allocation, funding arrangements, work management and job evaluations and other core focus are included in the standard range. While the "standard" according to its own characteristics, to enhance the capacity of social services as a basic function of college sports work, so work in college sports can really become an effective carrier of the inheritance of cultural tradition and practice of cultural innovation.

"Basic standards" is strictly rules setting and implementation of the sports curriculum, by learning courses enable students to master the basics knowledge of scientific training, basic skills 
and effective way to learn at least two sports training program of a lifetime, to develop good exercise habits. Among them, the undergraduate students open not less than 144 hours (not less than 108 hours of college students) of physical education, physical education is not less than 2 hours per week, not less than 45 minutes per hour. Open sports electives courses for other grades and graduate students, elective courses scores is included students credit score. The number of students per PE class is not more than 30 students. To set up no less than 15 sports program. Each physical education class is to improve the training content of the students' heart and lung function, is not less than $30 \%$; reflect the quality of the students cardiopulmonary exercise program as test content, test scores right weight not less than $30 \%$.

Students physique monitoring and evaluation is very important work of the current school sports development, including four aspects:

(1) full implementation of the "National Student Physical Health Standards", the establishment of student physique health test center, arrange special personnel to take charge, and improve working conditions, for all students to carry out physical fitness tests each year, the test scores feedback to student, and the test results after the Ministry of education reported to the national physical health standard data management system, the formation of the school students physical health annual report. The overall results of the students' physical health tests are announced in time.

(2) The establishment of a sound "National Student Physique Healthy Standard" management system, student test scores included in the student records, as an important basis for the students appraised. After graduation, student test scores is not reach 50 points by graduation process (due to illness or disabled students, with a medical certificate to the school applied for and may be granted after examination by graduation). The test scores passing grades rate of the graduation grade students is more than $95 \%$.

(3) The physical health of students as an important indicator to measure the level of school running. The physical health status, physical education scores, participation in physical activity and other things as the important content of students comprehensive quality evaluation.

(4) the establishment of student physical health status analysis and judgments mechanisms, develop interventions based on students' physical health status, as the case may take the necessary measures to classify teaching and individual counseling, guiding students and carry out physical activity, effectively improve sports work, to improve all students' physical health condition.

Sports test grade is divided into excellent, good, pass and fail. Boys' and girls' score standards and test items are different. Test items include vital capacity and body mass index, run 1000 meters, 800 meter run, step test, 50 meter run, standing long jump, throwing solid ball, grip body mass index, chin up, sit ups, sitting body flexion, rope skipping, basketball dribbling, soccer ball dribbling, volleyball and other.

\section{Functional Design}

Sports test scores of students registered and query software, including administrators, students and teachers of three types of users, different types of users with different privileges, the administrator is responsible for creating users and assign permissions. Among them, the administrator users are mainly system maintenance and management functions; student users are mainly query functions, and each student can query their scores; teachers users mainly scores registration, each teacher can register their own students' test scores. Sports test scores of students registered and query software, the main function module design as shown in Fig. 1.

Students basic information maintain module. This module is mainly responsible for entry, modification and deletion of data, such as students' basic information table. Students' basic information table with student scores table through school number field is associated, for browsing and querying a student's scores to service [2]. Meanwhile, student scores management can add scores information, can also modify student scores information, but also can carry on delete operation. 
Scores management is the core module of software, mainly contains scores registered, query, add, modify, and delete functions, depending on the operating permissions of system user, which have different functions.

Scores registration is scores entry: Teachers can entry their own class student scores, class as a unit to entry. After teacher login system successfully, entering scores input interface. Because teachers can hold the same subject may be assigned to more than one class teaching, so scores entry page defaults to the current teachers can input the list of subjects. After the teachers to choose entry subjects, will enter a list of class on current discipline. After the teacher once again select the class, will enter into the class scores entry. Entry scores can be divided into: class scores unified entry, the individual student scores entry [3]. Query scores: class unified query scores, the individual student scores queries. Student users can query their scores according to their student number. At the same time, there are doubts about their scores, can give the teacher a message on the message board, teachers to re-examine the student's scores.

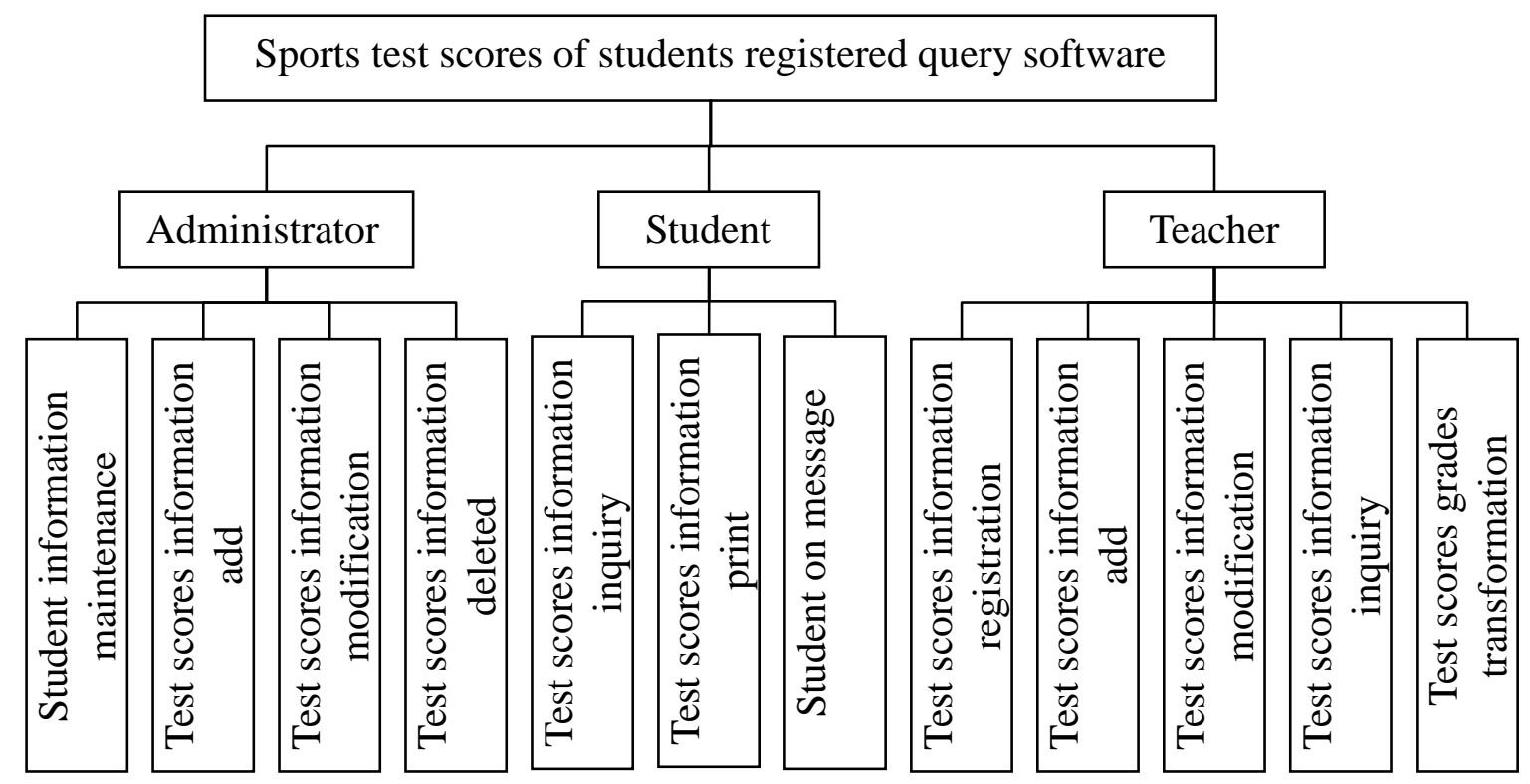

Fig. 1. Function module structure

Sports grades transformation, sports final scores from the individual assessment results for each sport, as well as physical health test scores and usual score in accordance with a certain proportion of the comprehensive assessment, and according to the scores to transformed scores grades, grades are divided into five grades: excellent, good, medium, pass and fail [4].

\section{Table Logical Structure Design}

Data table is a very important object in the database, is the basis of other objects. Date table should be designed in accordance with certain principles to classify for information, as well as to ensure the reasonableness of the table structure design, in order to reduce data entry errors, and allows the database to work efficiently. The software uses SQL Server 2005 database, the main data table logic structure design include:

Students basic information table is mainly used to store the student's basic information, field mainly includes student number, password, name, sex, department, health, natural class name, sports class and other information, taking into account the situation of sports elective courses, Therefore, the sports elective class name and natural class name to distinguish settings, to achieve the requirements of the information clearly.

Physical health test scores registration form primarily to save the National Physical Fitness Test Center test scores specified projects scores, mainly field includes classroom teachers, grades, sports class, student number, weight, height and weight scores, vital capacity scores, endurance performance, flexible power project performance, speed dexterity project performance[5].

Logical structure design of sports scores registration data table is shown in Table 1. Sports scores 
registration form is mainly used for storage of student sports score data. Fields mainly include: Test date, school year number, grade number, sports classes name, natural classes number, natural classes name, student number, student in departments, national code, student name, student sex, student height, student weight, vital capacity, usual score, physical fitness test total score, physical education examination, rewards and punishments project results, sports score total point, test situation, classroom teachers, remarks.

Table 1. Sports scores registration form

\begin{tabular}{c|c|c|c|c|c|c|c}
\hline \multirow{2}{*}{$\begin{array}{c}\text { Fields } \\
\text { NO }\end{array}$} & $\begin{array}{c}\text { Fields } \\
\text { Name }\end{array}$ & $\begin{array}{c}\text { Fields } \\
\text { Type }\end{array}$ & $\begin{array}{c}\text { Fields } \\
\text { Width }\end{array}$ & $\begin{array}{c}\text { Fields } \\
\text { NO }\end{array}$ & $\begin{array}{c}\text { Fields } \\
\text { Name }\end{array}$ & $\begin{array}{c}\text { Fields } \\
\text { Type }\end{array}$ & $\begin{array}{c}\text { Fields } \\
\text { Width }\end{array}$ \\
\hline 1 & TestDate & Datetime & 8 & 12 & StHeight & Smalldatetime & 4 \\
\hline 2 & SyNo & Nvarchar & 20 & 13 & StWeight & Nvarchar & 20 \\
\hline 3 & GradeNo & Nvarchar & 20 & 14 & VC & Nvarchar & 20 \\
\hline 4 & SclassName & Nvarchar & 20 & 15 & Uscore & Nvarchar & 20 \\
\hline 5 & NclassNo & Nvarchar & 20 & 16 & PFtscore & Nvarchar & 20 \\
\hline 6 & NclassName & Nvarchar & 20 & 17 & PEexam & Nvarchar) & 20 \\
\hline 7 & StNo & Nvarchar & 20 & 18 & RPscore & Nvarchar & 20 \\
\hline 8 & StDepart & Nvarchar & 40 & 19 & TotalScore & Nvarchar & 20 \\
\hline 9 & Nation & Nvarchar & 20 & 20 & TextS & Nvarchar & 20 \\
\hline 10 & StName & Nvarchar & 20 & 21 & StTeacher & Nvarchar & 30 \\
\hline 11 & StSex & Nvarchar & 10 & 22 & Remark & Nvarchar & 20 \\
\hline
\end{tabular}

\section{Detailed Design}

The detailed design is further refined to outline design, two internal characteristics determine the module, which describes the implementation process of the each module and the local data structure of definition module. For detailed design tool, to be able to provide unambiguous description of the design, can be specified in the control flow, processing function, data organization and other implementation details, thus in the programming stage, design description can be directly translated into program code. Detailed design tools include a lot of, this paper selects IPO diagram, IPO diagram of the "registered and query scores" module is shown in Fig. 2.

Input

Process

Output

\begin{tabular}{|c|c|c|}
\hline \begin{tabular}{|c} 
Student number \\
Student name \\
Classroom classes \\
Classroom teacher \\
Natural class NO \\
Natural class name
\end{tabular} & $\begin{array}{l}\text { Select the registered scores mode, class } \\
\text { scores unified registration, registration of } \\
\text { individual student scores. Enter registration } \\
\text { interface for scores registration, after the } \\
\text { registration, check the correctness of student } \\
\text { scores entry, and then enter the calculation } \\
\text { of the total score and grades conversion, the } \\
\text { software automatically rankings, generate } \\
\text { lists. } \\
\text { Select query score mode: class unified } \\
\text { query scores and a single student score } \\
\text { query, enter the query interface, teacher can } \\
\text { browse the score, prints scores list. }\end{array}$ & $\begin{array}{c}\begin{array}{c}\text { Students' individual score } \\
\text { output } \\
\text { Class scores unified output } \\
\text { Scores ranking list output } \\
\text { Print output }\end{array}\end{array}$ \\
\hline
\end{tabular}

Fig. 2. IPO diagram of registered query scores module

IPO diagram is a tool for the detailed design of each module, it is referred to the input process output graph, which is initiated and perfected by the IBM Corporation in the United States as a tool. Module structure diagram of the system in the formation process, resulting in a large number of 
modules, during the detailed design and developers should write a description for each module. IPO diagram is an important tool used to illustrate the input of each module, the output data, and data processing. The main part of IPO diagram is the algorithm description section, which may adopts structured language, decision tables, decision trees, may also be used N-S chart, the problem analysis diagram and process description languages and other tools, to be accurate and concise description of the module execution details. In the IPO diagram, the input and output data is from the data dictionary. Local data items refer to internal use data for individual module; it has nothing to do with the other parts of the system, only by this module definition, storage and use. Notes are the necessary instructions for the relevant problems of this module. Developers can not only use IPO diagram to module design, but also can use it to evaluate the overall design. Users and managers can use IPO diagram to write, modify and maintain procedures. Thus, IPO diagram is a kind of important documentation in system design stage [6].

\section{Conclusion}

Sports test registered and query software is an integral part of the college, it not only provides users with sufficient information and efficient query method, to allow students easy access to their own sports test scores and information, but also to facilitate administrator for student scores information add, modify, delete, query, message and other operations. But the students' sports scores is always relying on traditional manual way, this management approach, there are many shortcomings, such as low efficiency, poor security, search, update and maintenance difficulties, and so on [7]. The software in this article for student' sports scores information management, have unable parallel handwork administration merit, such as rapid retrieval, easy to find, high reliability, large storage capacity, good security, long life, low cost, these advantages can greatly improve students' sports scores management, query efficiency, to achieve students' sports scores information management automation, systematic and standardized.

\section{References}

[1] Ch. F. Li, "Design and Implementation of Vocational Students' Sports Score Management System," Xiamen University, 2014.

[12] Baidu Encyclopedia, "Basic standards of physical education in Colleges and Universities," http://baike.baidu.com/link?url=ftyNsmh4i9OuEgfaEpuDT-h3_OFM59fy3VP5Wv1vYu5j_8N Lrdi6pr3FlPdYNc2P351md9spSNMjjrWtsjdYG_, 2015-3-25.

[2] W. Sun, "Design on School Sports and Health Performance Management System," Journal of Tianzhong, vol. 19, no. 5, pp. 55-56, 2004.

[3] J. Chen, "Design and Implementation of Mandarin School Student Achievement Management System Based on Web Architecture," University of Electronic Science and Technology of China, 2011.

[4] Sh. W, "Design and Implementation on Sports Achievement Management System," Journal of Panzhihua University, vol. 28, no. 6, pp. 42-46, 2011.

[5] W. Shen, "Research and Development on Students' Sports Performance Management System Based on B/S Mode," China Computer and Communication, vol. 6, no. 2, pp. 52-53, 2012.

[6] Baidu Know, "IPO diagram and detailed design," http://zhidao.baidu.com/link?url=wSSsA00NOVV2SnHxwTjDo2K_rtMKpwRrp79Vhn7k6CK vquhLzeuWanULF7O5Xzo_ILD_U2LTo3PrRNcQNiVfa9BTANpmd5xIVURyb4hfDGS, 2014-10-5.

[7] Y. F. Lu, "Research and Design on Students' Performance Inquiry System Based on ASP Technology," Journal of Anyang Institute of Technology, vol. 9, no.6, pp. 61-65, 2010. 